\title{
ESPAÇO DISCURSIVO E/OU PRÁTICA DE LINGUAGEM? O FESTEJO DA SANTA E DA CONGADA EM ESPÍRITO SANTO DO DOURADO - MG
}

\author{
Andrea Silva Domingues ${ }^{1}$ \\ Benedita Celeste de Moraes Pinto ${ }^{2}$ \\ Danilo Gianini Docema ${ }^{3}$
}

\begin{abstract}
Resumo
As festas de santos(as) e as Congadas são acontecimentos históricos e discursivos presentes no calendário festivo e eclesiástico dos homens e mulheres que residem no sul de Minas Gerais; do mesmo modo que são espaços em que discursos se materializam nas mais variadas formas para a realização de práticas culturais que se (re)significam e produzem novos sentidos anualmente. Dessa maneira temos como ponto de interesse para este texto interpretar [da] Festa de Nossa Senhora do Rosário e a Congada da/na cidade de Espírito Santo do Dourado MG como espaço discursivo e/ou prática de linguagem, bem como observar como o discurso pode se materializar no sujeito congadeiro(a), produzindo efeitos de sentido. Metodologicamente, adotamos a prática da história oral, tendo como corpus de análise recortes de narrativas orais. O trabalho foi desenvolvido no diálogo entre a Análise de Discurso e a História Social, um percurso que nos conduziu a compreender como os sujeitos sociais constituem o discurso, a cultura na e pela linguagem como produtora de sentidos e resistência no tempo presente.
\end{abstract}

Palavras-chave: Discurso. Linguagem. História. Cultura Afro-brasileira.

\section{DISCURSIVE SPACE AND/OR LANGUAGE PRACTICES? THE FESTIVITY OF THE SAINT AND THE CONGADA IN ESPÍRITO SANTO DO DOURADO - MINAS GERAIS STATE}

\begin{abstract}
The festivities of some Saints and the Congadas are historical and discursive events present in the calendarial and ecclesiastical festivities for men and women who live in the southern part of Minas Gerais state, Brazil, as well as they are spaces in which discourses are materialized on many variety of forms to perform cultural practices the (re)mean and produce new meanings annually. So, we have as a bridge of interest for this text to interpret the Nossa

\footnotetext{
${ }^{1}$ Universidade Federal do Pará (UFPA), Pará - Brasil. Doutora em História Social pela Pontifícia Universidade Católica de São Paulo (PUC-SP). Docente e pesquisadora visitante sênior do Programa de Pós-graduação em Educação e Cultura do campus Universitário do Tocantins - Cametá, da Universidade Federal do Pará, pelo PROCAD AMAZÔNIA (UPA / UFAM / UFMT). ORCID: http://orcid.org/0000-0002-9264-7754. E-mail: andrea.domingues@gmail.com.

${ }^{2}$ Universidade Federal do Pará (UFPA), Pará - Brasil. Doutora em História Social pela Pontifícia Universidade Católica de São Paulo (PUC-SP). Professora Adjunta A III da Universidade Federal do Pará, lotada no Campus Universitário do Tocantins/Cametá, onde atua na Faculdade de História do Tocantins (FACHTO) e no Programa de Pós-Graduação em Educação e Cultura (PPGEDUC). ORCID: http://orcid.org/0000-0001-9450-5461. E-mail: celpinto18@gmail.com.

${ }^{3}$ Rede Estadual de Ensino do Estado de Minas Gerais. Diretoria Municipal de Eventos Culturais da Prefeitura de Espirito Santo do Dourado - MG. Mestrado em Ciências da Linguagem pela Univás. Professor da Rede Estadual de Ensino de Minas Gerais e do Colégio Foch Pouso -MG Alegre. Atualmente é Diretor Municipal de Eventos Culturais da Prefeitura da cidade de Espirito Santo do Dourado - MG. ORCID: http://orcid.org/0000-00029581-3949. E-mail: disensol.ufpa@gmail.com.
} 


\section{Linguagens - Revista de Letras, Artes e Comunicação - ISSN 1981-9943 \\ Blumenau, v. 13, n. 2, p. 334-350, maio/ago. 2019 \\ DOI: http://dx.doi.org/10.7867/1981-9943.2019v13n2p334-350}

Senhora do Rosário and Congada festivities from/in the city Espírito Santo do Dourado Minas Gerais state as a discursive space and/or language practices, and also to observe how discourse can be materialized on the subject called congadeiro (a) producing effects of meaning. This work has been developed methodologically based on the dialog between the Discourse Analyses and Social History, a pathway that led us to understand how the social subjects arrange the discourse; the culture on and through language as a producer of meanings and the resistance in our time.

Keywords: Discourse. Language. History. Afro Brazilian culture.

\section{PRELIMINARES}

Os estudos realizados sobre os festejos populares no Brasil tornaram-se uma temática muito abordada por pesquisadores de diferentes áreas do saber, principalmente das Ciências Humanas; a categoria festa traz diferentes sentidos, por ser o festejo momentos onde se confrontariam as tensões de um universo ainda não regulado, onde a cultura popular concentra, utiliza como espaço de disputa e de subversão (BAKHTIN, 2013).

As festas de Congada e de santos(as), no Sul de Minas Gerais, não fogem dessa perspectiva, são espaços de sociabilidade, de lazer, de disputa de poder, de fé;. consideradas práticas de resistências à tradição que se inserem no campo da cultura popular, afinal, o campo da cultura é um campo de disputa, de conflito de classe, que não é homogêneo (WILLIAMNS, 1979).

O que diferencia este artigo de muitos estudos efetuados até o momento é que realizamos uma interpretação do festejo religioso e de Congo como espaço discursivo e/ou prática de linguagem, em que os discursos se materializam e se significam colocando, em funcionamento no e pelo corpo de cada sujeito, diferentes linguagens, causando efeitos de sentidos que movimentam esse acontecimento discursivo e histórico, trazendo representações de práticas culturais de tempos remotos da cultura afro-brasileira, como a Congada que é:

\footnotetext{
Considerada uma das manifestações culturais mais presente no imaginário dos homens negros, primeiro dos escravos e posteriormente dos homens livres, a dança de Congo, a chamada Congada, tem um papel fundamental no festejo de Nossa Senhora do Rosário, podendo ser entendida como um processo de afirmação dos homens negros, que através desta prática reafirmam experiências e formas de resistências (DOMINGUES, 2017, p. 125).
}

É sobre este espaço de linguagens e acontecimento discursivo que discutimos o festejo e Congada da/na cidade de Espírito Santo de Dourado em Minas Gerais, que é realizado no último final de semana do mês de julho há mais de oitenta anos. Trata-se de mais 


\section{Linguagens - Revista de Letras, Artes e Comunicação - ISSN 1981-9943 \\ Blumenau, v. 13, n. 2, p. 334-350, maio/ago. 2019 \\ DOI: http://dx.doi.org/10.7867/1981-9943.2019v13n2p334-350}

uma das festas que pertencem a uma rede de acontecimentos religiosos, realizados em cidades do Vale do Sapucaí no Sul de Minas Gerais, que apresentam diferentes formações discursivas e se significam no processo de construção identitária de homens e mulheres negras do tempo presente produzindo efeitos de sentidos.

As práticas culturais africanas e afro-brasileiras estão presentes de diferentes maneiras na memória histórica do Sul de Minas, representadas nos discursos, nos processos de construção identitária de cada sujeito que se constituem, se formulam para manter práticas, saberes dos tempos do cativeiro. Uma das formas simbólicas desta representação é a cidade de Espírito Santo do Dourado, localizada no sul/sudoeste de Minas Gerais. Economicamente, a cidade gira em torno da agropecuária tendo como principais produtos a batata inglesa, milho, feijão, mandioca salsa, banana, morango, sendo esta última a cultura que transformou a cidade numa das maiores produtoras do Brasil, o que está atraindo cada vez mais a chegada de migrantes do Norte/Nordeste do país, como Tocantinenses, Paraenses e Maranhenses e a criação de gado leiteiro e de corte. Nesta cidade, também há vários comércios e indústrias (têxteis, alimentícia e de chicote de motos), gerando empregos e movimentando o investimento na cidade por parte dos migrantes como dos próprios habitantes (INSTITUTO BRASILEIRO DE GEOGRAFIA E ESTATISTICA, 2019).

Com o objetivo de compreender o festejo de Santo e a Congada na cidade de Espirito Santo do Dourado-MG, buscamos dialogar com homens e mulheres que habitam a cidade e que vivenciam o festejo ou a Congada de alguma maneira. Partindo deste material e no intuito de dar visibilidade a sujeitos sociais envolvidos com esses acontecimentos, estabeleceu-se um contato inicial com congadeiros(as) e moradores (as) que participaram e participam das festividades.

Neste diálogo informal de reconhecimento do objeto de estudo, nos foi possível estabelecer contato com diferentes sujeitos para realização das entrevistas, tendo sempre em vista que:

O trabalho de campo é, por necessidade, um experimento em igualdade, baseado na diferença. É preciso que sempre exista uma linha de diferenças, que depois de transpostas, torne-se plena de significado, mas é necessário que exista também uma "linha", segundo o qual possamos comunicar o desejo de encontrar um terreno e uma linguagem comuns que possibilitem a troca" (PORTELLI, 1997, p. 13).

O texto aqui apresentado foi trilhado neste trabalho de campo, na busca da troca da linguagem, do aprendizado constante de experimentos de igualdades que possuem o desejo e o diferente na fala de cada narrador, considerando sempre que o sujeito narrador é participante 


\section{Linguagens - Revista de Letras, Artes e Comunicação - ISSN 1981-9943 \\ Blumenau, v. 13, n. 2, p. 334-350, maio/ago. 2019 \\ DOI: http://dx.doi.org/10.7867/1981-9943.2019v13n2p334-350}

ativo do estudo que realizamos, que o momento da entrevista é momento de partilha de saberes e como pesquisadores(as) podemos até ter status, mas são os narradores e narradoras que têm informações, e gentilmente compartilham conosco. (PORTELLI ,1997)

Como analistas de discurso e historiadores(as) sociais, é importante destacarmos que trabalhar com a história oral significa que estamos falando não com "fontes", que narram fatos, nem estamos por elas sendo ajudados, mas estamos dialogando com sujeitos sociais, nascidos de e na linguagem, interpelados pela ideologia, que partilham saberes, experiências de vida, discursivizam pela memória suas lembranças dos acontecimentos vividos ou ouvidos. A proposta do encontro com os narradores vem sendo na tentativa de traçar essa relação em que possa fazer com que esses não se sintam apenas um objeto de estudo, mas, sim, que o momento do diálogo seja importante para eles pela melhor razão que quiserem, na qual são considerados sujeitos em movimento, produtores de cultura, de discurso, de memória e não apenas uma máquina de informações.

A prática da história oral baseia-se na arte da escuta do outro, em aprender aquilo que o próximo tem a ensinar, não importando o lugar que ocupa na sociedade, considerando sempre que todos os sujeitos são iguais, e possuem a mesma importância na narrativa dos acontecimentos, pois "quando fazemos uma entrevista invadimos a privacidade de outra pessoa e tomamos seu tempo. Sendo a arte essencial do historiador oral a arte de ouvir." (PORTELLI, 1997, p. 21), sendo desta forma a arte de ouvir uma função essencial para os pesquisadores que trabalham com narrativas orais.

A pesquisa que apresentamos neste texto aborda uma dimensão diferenciada, buscamos o interpretar [da] festa de Nossa Senhora do Rosário e a Congada da/na cidade de Espírito Santo do Dourado-MG como espaço discursivo e/ou prática de linguagem pelas memórias e discursos produzidos pelas narrativas orais dos sujeitos que vivenciam os acontecimentos, tendo como ponto de partida a linguagem, pois como nos diz Orlandi (2009) é pelo discurso que podemos compreender os modos pelos quais se dá a individuação do sujeito. Os processos identitários se fazem em diferentes espaços de memória.

Trabalhar com o discurso é trabalhar com sujeitos e com a sociedade, compreendendo como o simbólico faz sentido e como a sociedade se constitui em inúmeras manifestações da linguagem pensada na sua relação com as práticas sociais, históricas, políticas e econômicas, produzindo sentidos que se concretizam em seus diferentes espaços e tempos. 


\section{Linguagens - Revista de Letras, Artes e Comunicação - ISSN 1981-9943 \\ Blumenau, v. 13, n. 2, p. 334-350, maio/ago. 2019 \\ DOI: http://dx.doi.org/10.7867/1981-9943.2019v13n2p334-350}

Festejos de santos como a festa de São Benedito e Nossa Senhora do Rosário são práticas culturais e experiências em várias cidades do sul mineiro, e, na atualidade, a sua discursividade presta homenagens aos homens e santos negros, realizando-se principalmente nas festas de Congada, na dança e no canto do Congo, que (re)significam lembranças do cativeiro.

Nas afirmações de Domingues (2017, p. 34), “compreendemos que a festa faz parte da cultura de seus participantes, que partilham um conjunto de valores e significados". Assim, podemos dizer que os dias de festa são momentos nos quais a população desfruta de particularidades e ações como fé, lazer e devoção, que se tornam importantes nessa condição de produção (festa/festejo). Os dias de festa também são momentos de reencontro, de retorno à terra natal, onde filhos, irmãos, familiares se reencontram, pois, apesar de muitos estarem residindo em outras cidades, retornam à cidade nos dias de festa para rever amigos e familiares, fazendo com que os momentos da festa também sejam um espaço de sociabilidade, nos quais homens, mulheres, jovens, crianças e idosos se reúnem para comemorar ou apenas se reencontrar.

As festas regionais que acontecem no sul de Minas (re)significam-se a cada ano nos discursos que determinam os diferentes sujeitos que se relacionam nestes acontecimentos históricos e discursivos; sujeitos estes afetados sempre pela ideologia que se constitui neste espaço de produção de novos discursos e atribuição de sentidos. Assim, percebemos os festejos como formas de significação que estão a cada ano produzindo novos discursos, novos sentidos nos participantes que vivenciam a história, não como um movimento linear, mas, sim, como movimento espiral com seus encontros e desencontros.

Muitas dessas festas têm caráter religioso e cada qual corresponde, em geral, à comemoração a um santo. Tais festas são caracterizadas como populares pelo fato de serem formadas por práticas cotidianas que envolvem grande parte da população da cidade e da região, mesmo que participem da atividade apenas como expectadores.

As festas são importantes elementos da cultura de um povo, através delas os grupos apresentam as suas histórias, suas danças, seus ritmos. Elas geralmente proporcionam uns dos poucos momentos de lazer de algumas sociedades, e é nelas que as pessoas se encontram, reveem amigos, têm seus namoros, reencontram parentes distantes, compram roupas novas, vão a feira e dançam um pouco mais (SOCORRO; DA SILVA, 2003, p. 10).

É no contexto dessas palavras que podemos pensar na festa de Nossa Senhora do Rosário na cidade de Espírito Santo do Dourado, tentando entendê-la como uma junção de valores, práticas e tradições que envolvem toda a sociedade, o lugar onde os discursos se 


\section{Linguagens - Revista de Letras, Artes e Comunicação - ISSN 1981-9943 \\ Blumenau, v. 13, n. 2, p. 334-350, maio/ago. 2019 \\ DOI: http://dx.doi.org/10.7867/1981-9943.2019v13n2p334-350}

materializam, onde percebemos os sujeitos inseridos em formações discursivas que se significam e se assujeitam, um lugar de afirmação e de resistência.

\section{A FESTA E A CONGADA: ESPAÇO DISCURSIVO OU PRÁTICA DE LINGUAGEM.}

Falar da festa como espaço discursivo nos leva a uma série de compreensões possíveis, e uma delas é perceber que é na festa que os sujeitos vivenciam e se identificam com a tradição do festejo, significando-se com o mundo simbólico do festejo, onde vários sujeitos em diferentes posições realizam práticas de linguagens, como a Congada.

Compreendemos o festejo de Nossa Senhora do Rosário em Espírito Santo do Dourado como parte constituinte dos discursos da sociedade douradense, tendo na prática da Congada uma manifestação tradicional emblemática na formação destes discursos, que estão inseridos na sociedade e nos sujeitos douradenses, sendo uma prática de linguagem em movimento, que se (re)significa a cada vez que uma palavra é enunciada, que se constitui em seu funcionamento.

Ao interpretar os discursos que rodeiam o festejo na cidade de Espírito Santo do Dourado e para compreender os sentidos que constituem a Congada como prática de linguagem neste espaço discursivo, é fundamental considerarmos que "o sujeito se dá no e pelo discurso, pois, o sujeito sempre é o sujeito do discurso" (ORLANDI, 2010, p. 15). Portanto, pensar em história na Análise de Discurso é estar dialogando com as condições de produção dos discursos e que estão relacionados às relações de poder do lugar ocupado pelo sujeito do discurso e seus interlocutores.

Pêcheux (1975) já dizia não há discurso sem sujeito e não há sujeito sem ideologia: o indivíduo é interpelado em sujeito pela ideologia e é assim que a língua faz sentido. Nesse mecanismo, o sujeito para se significar tem que se inscrever na história, onde ideologia e inconsciente estão materialmente ligados pela língua.

Trabalhar com a História e a Análise de Discurso é poder trazer à tona muitas histórias e outras memórias dos participantes do festejo, entendendo também a festa como uma manifestação de linguagem, que mais fortemente podemos ver nas Congadas, nas quais inúmeros sujeitos participam e se fazem vistos e ouvidos, seja nas canções, nas danças, nas performances que fazem da Congada uma prática de linguagem, que está inserida dentro do espaço discursivo que é a festa. 


\section{Linguagens - Revista de Letras, Artes e Comunicação - ISSN 1981-9943 \\ Blumenau, v. 13, n. 2, p. 334-350, maio/ago. 2019 \\ DOI: http://dx.doi.org/10.7867/1981-9943.2019v13n2p334-350}

Entendemos que existem diferentes redes de memória discursiva, que são assegurados pela linguagem e que o sujeito, efeito da linguagem, (re)produz dizeres de diferentes redes. Dessa forma, entendemos que a Congada é uma resultante de um conjunto de redes de sentido que diz respeito ao interdiscurso, que não é a memória individual relacionada a lembranças, mas sim discursiva, na produção e configuração dos sentidos nos quais a Congada passa a ser entendida como um efeito de sentido, tendo como base a linguagem.

A Congada é então uma prática de linguagem, constituída por diferentes processos discursivos, ou seja, por diferentes modos de se dizer, diferentes modos de processos de significação. Os processos discursivos constituem as práticas discursivas, nas quais há certa estabilidade do(s) sentido(s), pois "não se tem o direito de se dizer tudo, que não se pode falar de tudo em qualquer circunstância, que qualquer um, enfim, não pode falar de qualquer coisa" (FOUCAULT, 1996, p. 9). Há, nas práticas discursivas, as produções de certas repetições dos e nos dizeres.

Constituir-se congadeiro(a) é estar presente na sociedade, ocupando posições sujeito que são atravessados por mecanismos linguageiros que levam à produção de dizeres, que tendem a um dos sentidos numa determinada prática de linguagem, que, em dias de festa, celebrando os santos, cantando, dançando, estão ao mesmo tempo, embora em algumas circunstâncias de forma inconsciente, participando efetivamente de discursos, pois "toda palavra faz parte de um discurso e todo discurso se delineia na relação com outros discursos" (ORLANDI, 2010, p. 43); compreendendo assim que toda manifestação de linguagem pode ser um discurso, ou seja, as danças, as canções, celebrações são constituintes dos sujeitos, atravessados por interdiscursos, o já dito, de outros tempos que se fazem presentes nos dias atuais, tudo isso presente nas práticas de linguagem, como a Congada.

O espaço discursivo não é um espaço físico, mas, sim simbolizado no qual se inserem as formações discursivas, entendidas "como aquilo que, numa formação ideológica dada, ou seja, a partir de uma conjuntura sócio-histórica dada, determina o que pode e o que deve ser dito" (ORLANDI, 2012, p. 43). O sujeito congadeiro(a) inscreve-se nesse espaço entrando (colocando-se, por interpelação, identificação) na ordem discursiva própria às formas que constituem o espaço discursivo.

A prática de linguagem está relacionada ao que acontece no espaço discursivo. $\mathrm{O}$ modo como se diz em determinado espaço discursivo é próprio/específico da linguagem que este espaço abrange, assim como é próprio também desse espaço discursivo. Ao dizer de um modo e não de outro, um sujeito funciona discursivamente na prática e se inscreve no espaço. 


\section{Linguagens - Revista de Letras, Artes e Comunicação - ISSN 1981-9943 \\ Blumenau, v. 13, n. 2, p. 334-350, maio/ago. 2019}

DOI: http://dx.doi.org/10.7867/1981-9943.2019v13n2p334-350

Podemos compreender que o espaço discursivo aqui trabalhado é a festa e uma prática de linguagem importante é a Congada, sempre estando o espaço discursivo afetando e (vice-versa), o que significa dizer que há relação entre sociedade e linguagem.

Como nos diz Domingues (2017, p. 34) "compreendemos que a festa faz parte da cultura de seus participantes, que partilham um conjunto de valores e significados". Assim, podemos dizer que os dias de festa são momentos nos quais a população desfruta de particularidades e ações como fé, lazer e devoção que se tornam importantes, produzindo diferentes interpretações, gerando efeitos de sentido que muitas vezes fazem surgir novos dizeres.

Figura 1: A Congada na Festa de Nossa Senhora do Rosário em 2019.

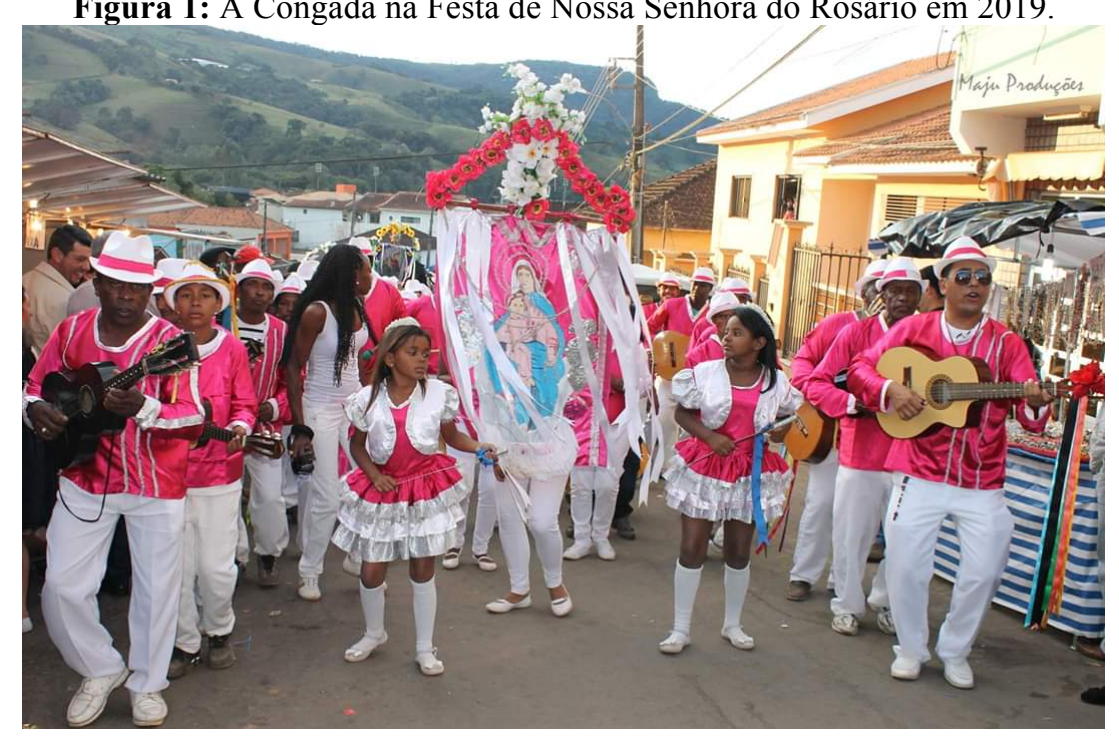

Fonte: Fotografia cedida por Danilo G. Docema.

Na Figura 1, observa-se a festa como espaço discursivo e a Congada como prática de linguagem. Em dias de festa, a Congada percorre as ruas da cidade onde a festa ocorre, estando a população e a Congada dividindo o mesmo espaço, que é físico e ideológico. Os diferentes sujeitos que participam do festejo passam a se significar e (re)significar atravessados pelos discursos que se materializam na festa.

Perceber a Congada como produtora de sentidos é entender que os sujeitos se inserem historicamente na sociedade e a história se inscreve pelo discurso, pois o sujeito sempre é o sujeito da linguagem, e compreendemos que a Congada é uma manifestação de linguagem, através da dança, dos cantos, das batidas, suas significações e seus sentidos, retomam um discurso sobre o passado de lutas e resistências. 


\section{Linguagens - Revista de Letras, Artes e Comunicação - ISSN 1981-9943 \\ Blumenau, v. 13, n. 2, p. 334-350, maio/ago. 2019 \\ DOI: http://dx.doi.org/10.7867/1981-9943.2019v13n2p334-350}

Na Figura 1, ainda é possível alcançarmos uma análise das vestimentas dos sujeitos que dançam a Congada, denominados congadeiros(as), em suas vestes percebemos que está arraigada uma memória que remonta a um passado constitutivo da história dos afrobrasileiros. As cores chamativas das roupas que são usadas pelos(as) congadeiros(as) é uma forma de (re)significar e destacar que a história afrodescendente ainda é marcante na sociedade douradense, pois, ao usarem estas roupas, os(as) congadeiros(as) estão ocupando esta posição sujeito e se constituindo no processo identitário que marca a prática de linguagem da Congada no sul de Minas Gerais.

Figura 2: O reinado da Congada. Festa do ano de 2015

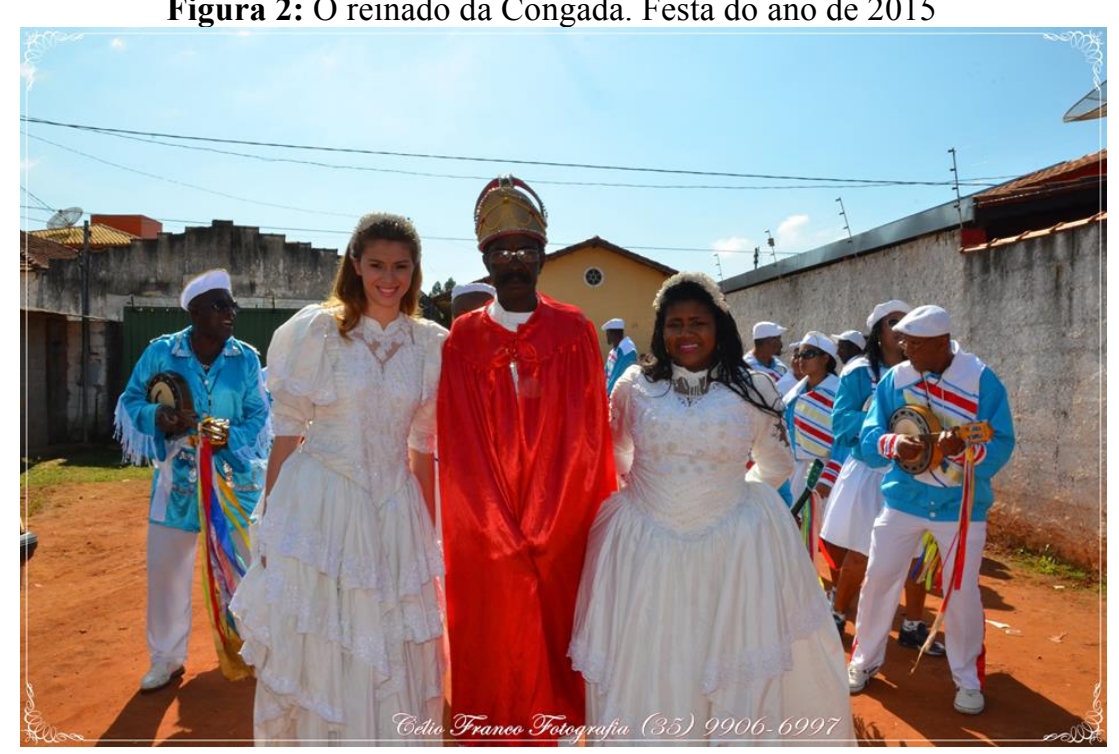

Fonte: Fotografia cedida por Célio Franco, morador da cidade de Espírito Santo do Dourado-MG.

As vestimentas (Figura 2) usadas pelos congadeiros(as) tornam-se no espaço do festejo de Nossa Senhora do Rosário e na prática da Congada uma manifestação da linguagem, pois existe dentro do terno de Congo (grupo de congadeiros(as) uma hierarquia a ser seguida, como, por exemplo, o indivíduo de vermelho simbolizando o rei, acompanhado por sua rainha e sua princesa, logo atrás a formação dos dançarinos, cantores, batedores de caixa entre outros. Manifestação de linguagem, porque as vestimentas representam os sentidos que fazem dos sujeitos congadeiros sujeitos sociais, participantes importantes do festejo.

$\mathrm{Na}$ formação da Congada, como se observa na Figura 2, as posições ocupadas pelos congadeiros(as) seguem a hierarquia de uma monarquia, com rei, rainha e princesa e súditos, sendo essa representação ecoada discursivamente e corporalmente no cortejo da Congada nos remetendo às memórias do passado de um tempo de cativeiro da história africana. 


\section{Linguagens - Revista de Letras, Artes e Comunicação - ISSN 1981-9943 \\ Blumenau, v. 13, n. 2, p. 334-350, maio/ago. 2019 \\ DOI: http://dx.doi.org/10.7867/1981-9943.2019v13n2p334-350}

Antes de os europeus dominarem econômica e politicamente o continente africano, as diversas etnias mantinham relações sociais diversas, e uma dessas formações nos remete à monarquia, como no caso do país Congo, localidade da qual se origina o nome da Congada. Historicamente, os povos africanos, no processo de escravidão, foram brutalmente trazidos para serem tratados como mão-de-obra escrava no Brasil.

Trabalhar com o festejo, com a Congada, dentro da festa, é estar em constante debate com a história dos sujeitos que constituem os modos de se viver, de se fazerem presentes na sociedade. Através da memória discursiva não serão revelados os sentidos da festa, mas os já ditos, cristalizados, vivenciados (re)significados nestes acontecimentos, pois "a memória [...] é o saber discursivo que faz com que, ao falarmos, nossas palavras façam sentidos. Ela se constitui pelo já-dito que possibilita todo dizer" (ORLANDI, 2010, p. 64).

A Congada é o lugar em que os(as) congadeiros(as) reafirmam e constroem suas identidades, são sujeitos de diferentes gerações, homens e mulheres, que, ao som dos tambores, acabam se unificando, fazendo dessa prática de linguagem uma forma de sociabilidade, de lazer, de resistência, de fé , aonde os sujeitos trocam experiências a todo momento, produzindo efeitos de sentidos, de como ser congadeiro(a).

Pensar nos homens e mulheres que fazem parte do festejo, partindo do pressuposto que se fazem constituídos na sociedade, através de seus discursos, que se inscrevem na história por meio da linguagem, é estar atento às inúmeras possibilidades de enxergar os sujeitos se significando e sendo significados, portanto, esses sujeitos sempre afetados pela ideologia são transformados nos sujeitos dos discursos, assim:

O sujeito é sempre e, ao mesmo tempo, sujeito da ideologia e sujeito do desejo inconsciente e isso tem a ver com o fato de nossos corpos serem atravessados pela linguagem antes de qualquer cogitação (HENRY, 1992, p. 188).

Foi com essa percepção que buscamos como pesquisadores da e na linguagem olhar para os sujeitos envolvidos no festejo de Nossa Senhora do Rosário e na Congada da cidade de Espírito Santo do Dourado no Sul de Minas Gerais, nas suas variadas formas, na sua relação com o passado a partir do presente, percebendo que as diferenças e mudanças se dão pelas muitas memórias que realizam um ir e vir nas lembranças através da arte de falar, de dançar de cantar, de se expressar.

\section{NARRATIVAS ORAIS E DISCURSO}




\section{Linguagens - Revista de Letras, Artes e Comunicação - ISSN 1981-9943 \\ Blumenau, v. 13, n. 2, p. 334-350, maio/ago. 2019 \\ DOI: http://dx.doi.org/10.7867/1981-9943.2019v13n2p334-350}

Ao narrar suas experiências de vida o sujeito (narrador) partilha seus saberes mais íntimos, silenciados, sagrados, não ditos e por este motivo "a história oral tem sido uma das grandes contribuições ao estudo das experiências de homens e mulheres em diversos e diferentes setores da sociedade, abrindo um caminho de conhecimento e possibilidades de valorização de grupos sociais até então invisíveis na documentação escrita". (DOMINGUES, 2012, p. 210).

As narrativas orais podem ou não ajudar o pesquisador / o analista de discurso a perceber o contorno que a vida vai construindo em sociedade, através dos caminhos que os trabalhadores vão traçando ao andar pelas ruas da cidade e do campo. Desta forma a história oral pode criar novos trajetos, desafios, inquietações de pesquisa, pois "uma entrevista é sempre uma lição de aprendizagem.” (PORTELLI, 2001, p. 16).

A Festa de Nossa Senhora do Rosário e a Congada são uma tradição que se inserem na sociedade da região do sul de Minas, praticamente todas as cidades vizinhas à Espírito Santo do Dourado praticam essa manifestação de linguagem; cada uma com suas particularidades. Nesse sentido, devemos ter a preocupação em situar aqui a categoria de memória discursiva, o já dito, o interdiscurso, percebendo o seu funcionamento no discurso, estruturada pelo esquecimento, como Courtine (1982) já dizia, "fala uma voz sem nome".

De acordo com Courtine e Marandin (1981, p. 24), o interdiscurso é o processo de reconfiguração incessante [...], representando tudo aquilo já dito e, também a ser dito. $\mathrm{O}$ interdiscurso é a base para a produção dos sentidos, visto que é o acúmulo de todos os dizeres já (re) produzidos e de todas as possibilidades de (se) dizer. É aquilo que fala antes, em outro lugar, independentemente: o já dito. Ele é tudo aquilo que já foi dito, produzido, e o que não foi ainda, mas está em potencialidade de ser dito.

Após ter apresentado ao leitor deste texto o festejo e a Congada como espaço discursivo e ou prática de linguagem utilizando de fontes imagéticas (Figuras 1 e 2), vamos entender um pouco mais sobre este acontecimento histórico e discursivo fazendo uso de alguns recortes de narrativas orais, construídas pela prática da história oral.

Ah, tem né, não é muita coisa né, mais vai seguido né, tem as barraquinhas, que vem de fora, faz doce pra vender, um tanto de coisa, a festa do Rosário, minha mãe fez meio pobre, teve uns 04 ternos de Congo, tinha o do padre, do João Sabino, meu irmão, os dos Pereira e 04 com o da Mata, 03 terno da cidade (Narrativa de Dona Egidia, 2009). 


\title{
Linguagens - Revista de Letras, Artes e Comunicação - ISSN 1981-9943 \\ Blumenau, v. 13, n. 2, p. 334-350, maio/ago. 2019 \\ DOI: http://dx.doi.org/10.7867/1981-9943.2019v13n2p334-350
}

Dona Egidia ${ }^{4}$, filha de uma das precursoras da festa na cidade, uma de nossas narradoras, mulher negra, residente de Espírito Santo do Dourado, com 84 anos, lúcida no ato de falar, transmite em sua narrativa uma memória atravessada por discursos do tempo presente e também de tempos remotos, pois ela explicita que em tempos atuais a festa vai seguindo, quando nos diz "mas vai seguindo né" mantendo a tradição desde a origem da primeira festa realizada na cidade de Espírito Santo do Dourado pela sua mãe no ano de 1939.

Dona Egidia ainda diz que, "tem as barraquinhas, que vem de fora”, demonstrando que festa tem participação externa a cidade em especial que tange ao comércio e no dizer, "minha mãe fez meio pobre", nos relata a condição financeira da festeira que era sua mãe, mas um dos sentidos possíveis desse dizer se refere à questão da participação da Congada, pois apenas 4 ternos de Congo participaram da festa, mostrando como a Congada é importante para os dias de festa, assim podemos pensar que o festeiro que consegue trazer para a cidade em dias de festa um grande números de Congadas, acaba fazendo uma festa imponente, um festejo para se inscrever na história, que através dessa prática de linguagem da Congada acaba produzindo sentidos que se constituem na memória dos sujeitos participantes do festejo.

\begin{abstract}
Os Congos quando vem aqui em casa, nossa, é uma bagunça, quando já sabe compro aquele tanto de guaraná pra servir, e eu queria sai, fechei a casa saí, a hora que eu cheguei ali fora aquele tanto ali esperando, vieram quietinho... Meus filho nunca dançou Congo, mas os neto vai... Muito bom, tão tudo bonito, e lá no Congo tem tudo, o mestre, a rainha, os que batem caixa, os que tocam viola pandeiro, tem as música, quando eles vai na casa do festeiro vai toma guaraná, agradece ,e essas músicas (Narrativa de Dona Vita, 2009).
\end{abstract}

Maria Vital de Jesus ${ }^{5}$, conhecida como Dona Vita, tem 63 anos, natural de Espírito Santo do Dourado e sempre residiu na mesma cidade, onde morou por muitos anos na zona rural do município, é viúva e tem 12 filhos, onde 8 filhos estão vivos, foi muitas vezes festeira e dançou Congo na sua adolescência.

Nas memórias de Dona Vita, no seu ato e lugar de fala, ela se significa e é significada perante a Congada, quando diz que "os Congo vem aqui em casa, nossa é uma bagunça, quando já sabe”, ela faz referência que a visita dos Congos em sua casa é sinônimo de alegria e comemorações, logo se identificando enquanto sujeito constituinte da Congada.

Observamos o interdiscurso em funcionamento, quando Dona Vita nos fala que "Meus filho nunca dançou Congo, mas os neto vai", percebe-se o sentido da Congada ser parte

\footnotetext{
${ }^{4}$ Egidia Maria de Jesus (in memoriam) narrativa gravada no dia 24/05/2009 na cidade de Espírito Santo do Dourado, documento transcrito, digitalizado e autorizado para uso e publicação.

${ }^{5}$ Maria Vital de Jesus, narrativa gravada no dia14/03/2009, na cidade de Espírito Santo do Dourado, documento transcrito, digitalizado autorizado para uso e publicação.
} 


\section{Linguagens - Revista de Letras, Artes e Comunicação - ISSN 1981-9943 \\ Blumenau, v. 13, n. 2, p. 334-350, maio/ago. 2019 \\ DOI: http://dx.doi.org/10.7867/1981-9943.2019v13n2p334-350}

constituinte da sua família, mesmo os filhos não dançando, não quer dizer que eles não façam parte dessa identidade, desse mundo que os rodeia, mas, no mesmo sentido, já colocando que os netos vão dançar, ou seja, aquilo que foi dito com ela, acaba sendo dito novamente (re) significado nos discursos futuros dos netos.

Essa memória discursiva, que se encontra na família de Dona Vita, acabou de fato mesmo acontecendo, no momento em que os netos deram continuidade na tradição discursiva da Congada, pois um dos narradores com quem dialogamos, Weberton ${ }^{6}$ é neto de Dona Vita e casado com sua prima, também neta de Dona Vita, ambos pertencentes ao Congado. Essa memória discursiva faz parte incessante da constituição dessa família, que ao passar dos anos mantêm em suas vidas o gosto pela Congada.

Ao dialogarmos com Weberton sobre os ternos de Congo que participam do festejo de Nossa Senhora do Rosário na cidade de Espirito Santo do Dourado, ele nos narra que:

Congadeiro daqui mesmo, amigo, uns vinte e cinco.

Mas tem congadeiros que vem de fora também, então uns trinta...trinta e cinco... lá de uns vinte e cinco.

É tudo primo e irmão. (Narrativa de Weberton, 2013)

Temos aqui então uma produção de sentidos que faz parte do cotidiano da família de Weberton / Dona Vita, na qual a condição de produção Congada se faz no/pelo discurso. Fazer-se presente na Congada e principalmente ser da família, representa para Weberton um sentimento de identificação, de alegria, não deixando que a Congada deixe de ser uma tradição, um discurso, até mesmo quando sujeitos chamados por ele de "fora", juntam-se para dançar, tocar, cantar, constituindo e fortalecendo mais a sua Congada, pois, para ele, esses sujeitos se tornam parte da família, tanto a de sangue, como também da irmandade do seu terno de Congo, quando nos afirma "É tudo primo e irmão", ser do Congo é ser da família, onde compartilham saberes e práticas diversas, onde se significam e se identificam, é um movimento de construção identitária.

O narrador Weberton de Paula é líder de um dos ternos de Congo (grupo de homens e mulheres que vivenciam e praticam a Congada) da/na cidade de Espirito Santo de Dourado, o qual tem como padroeiro São Benedito, Nossa Senhora do Rosário e Santa Ifigênia, três santos protetores dos homens pretos. Weberton é negro, trabalhador rural, tem 24 anos, é casado e morador da cidade.

\footnotetext{
${ }^{6}$ Weberton de Paula, narrativa gravada no dia17/04/2013, na cidade de Espírito Santo do Dourado, documento transcrito, digitalizado, autorizado para uso e publicação.
} 


\section{Linguagens - Revista de Letras, Artes e Comunicação - ISSN 1981-9943 \\ Blumenau, v. 13, n. 2, p. 334-350, maio/ago. 2019 \\ DOI: http://dx.doi.org/10.7867/1981-9943.2019v13n2p334-350}

Em nosso diálogo, quando Weberton é perguntado por que é o líder deste terno de Congo, o mesmo traz em sua narrativa os seguintes dizeres: "Pra não acaba a tradição, pra não acaba o Congo, falei "Vo monta um", e fui". O discurso do narrador traz com convicção de empoderamento; a importância, o sentido de responsabilidade de se manter significando e sendo significado pela prática cultural da Congada, uma tradição de tempos remotos.

Como dito anteriormente, o terno de Congo de Weberton possui o nome de três santos, a religiosidade se faz marcante na Congada, é parte da ideologia dos congadeiros, do mundo simbólico que estão inseridos, logo que ao ocupar uma determinada posição sujeito, a religiosidade é atravessada de inúmeros sentidos, mas nunca deixada de lado.

Foi de uma promessa que eu fiz, né, de um acidente que eu tive, eu quebrei a bacia, e falei, eu creio em São Benedito, e se ajuda eu a anda e de tudo certo eu vo pega a festa, e deu tudo certo e fiz a festa de São Benedito. .(Narrativa de Weberton, 2013)

Através da narrativa, "Foi de uma promessa," percebe-se como a fé religiosa em santos é visível e constituinte da vida de congadeiros (as); fé aqui no sentido de crença, “eu creio em São Benedito", confiabilidade e esperança, que através de seu pedido ele - Weberton confiou nos santos para que sua recuperação fosse abençoada.

Os santos como São Benedito e Nossa Senhora do Rosário são alguns dos mais populares entre os congadeiros(as), tanto que muitas Congadas levam os nomes do santos pelo fato de que os negros, desde a época da escravidão, escolheram esses para serem seus padroeiros. Existe uma variedade de manifestações que são aplicadas para homenagear os santos, dentre elas a prática de linguagem da Congada.

Desse modo, trabalhar com a festa de Nossa Senhora do Rosário e a Congada é lidar diretamente com a memória, com o interdiscurso, ou memória discursiva, pois, é através disso que percebemos a festa e a Congada como lugar do já dito, onde o sentido faz sentido e a tradição é vivida, aprendida pela oralidade, pelo ato de falar, de dançar, de ouvir e olhar. A Congada dentro da festa vai resistindo e mantendo viva uma tradição da cultura afro-brasileira em uma sociedade classista, machista, homofóbica e racista.

\section{4 À GUISA DE INCONCLUSÕES}

A Festa Nossa Senhora do Rosário e a Congada na cidade de Espírito Santo do Dourado no sul de Minas Gerais, analisada pelo viés da Análise de Discurso, passam a ser concebidas como um acontecimento em movimento, que não se restringem a fatos e 


\section{Linguagens - Revista de Letras, Artes e Comunicação - ISSN 1981-9943 \\ Blumenau, v. 13, n. 2, p. 334-350, maio/ago. 2019 \\ DOI: http://dx.doi.org/10.7867/1981-9943.2019v13n2p334-350}

acontecimentos que acabam se tornando um único sentido. A Análise de Discurso transforma esse único sentido em um leque de possibilidades, que tem no sujeito e na língua o seu diferencial. Já vimos que, para se significar, o sujeito se inscreve na história na/pela linguagem e percebemos isso, quando falamos que a Congada é uma prática de linguagem que se (re)significa anualmente e é vivenciada e discursivizada de geração em geração através da memória e da tradição oral e corporal.

Os sujeitos congadeiros(as) vivem e (re)significam lutas cotidianas, sendo assim a Congada é uma forma de viver sentidos diversos de tempos remotos, ligados à religiosidade, ao lazer, à sociabilidade, à família, à constituição do processo de formação identitária de homens e mulheres em sua maioria negros que muitas vezes estão à margem da sociedade.

Afirmamos desta forma que a Congada é uma prática de linguagem que constituí os sujeitos congadeiros(as) no seu espaço de significância que é o festejo.

A Análise de Discurso é uma disciplina, que nos permite estar em contato com inúmeras possibilidades de se compreender os sujeitos produzindo sentidos, ocupando determinadas posições sujeitos, dependendo das formações discursivas que estes sujeitos estejam inseridos. Nós, como analistas de discurso, compreendemos a importância da linguagem na constituição dos sujeitos e como não existe discurso sem sujeito e nem sujeito sem ideologia (PÊCHEUX, 1975) o diálogo com outras áreas como a História social torna-se fundamental para que possamos avançar na construção de novas possibilidades de análise.

Procuramos no corpo deste texto dialogar sobre a Festa de Nossa Senhora do Rosário e a Congada como espaço discurso e/ou prática de linguagem, sendo ambos constitutivos nos discursos da sociedade douradense, que ao longo dos tempos se (re)significa, produz novos sentidos nos sujeitos congadeiros(as), nos sujeitos festeiros, nos diversos sujeitos que participam da festa.

As vestimentas, os tambores, as danças, as canções, as expressões dos(as) congadeiros(as) em dias de festa, são os discursos que atravessam estes sujeitos. É no festejo e na Congada que eles passam a ser vistos e identificados pela sociedade, entrando em choque com o político; uma vez que compreendemos a Congada como um mecanismo de resistência a uma tradição elitizada que, desde os tempos remotos, excluem, marginalizam e silenciam os discursos desses que sujeitos que se fazem presentes em variadas posições sujeitos, seja o(a) congadeiro(a) em época de festa, seja ele pai, lavrador, religioso. Essa é a forma encontrada para quebrar, romper com o político, que individualiza esse sujeito na sociedade. 


\section{REFERÊNCIAS}

BAKHTIN. M. A cultura popular na Idade Média e no Renascimento: o contexto de François Rabelais. 8. ed. Trad. Yara Frateschi Vieira. São Paulo: Hucitec, 2013.

COURTINE, J. J. Définition d'orientations théoriques et construction de procedures en analyse de discourse. Philosophiques. Paris: 2, 1982. vol. IX.

COURTINE, J. J.; MARANDIN, D. Matérialités. In: Matérialités discursives. Sousla dir. de Conein, B., Courtine, J.J., Gadet, F., Pêcheux, M. Lille: Presses Universitaires de Lille, 1981. p. 21-33.

DOMINGUES, A. S; CARROZZA, G. História, memória e discurso. Revista Tempos Históricos, 2013, v. 17, p.141-161, 2 semestre de 2013. Disponível em: http://erevista.unioeste.br/index.php/temposhistoricos/article/view/9883. Acesso em 20 de abril de 2020 .

DOMINGUES, A. S. Cultura e memória: a festa de Nossa Senhora do Rosário na cidade de Silvanópolis. Pouso Alegre, MG: UNIVAS, 2017.

FOUCAULT, M. A ordem do discurso. São Paulo: Loyola, 1996.

HENRY, P. A ferramenta imperfeita: língua, sujeito e discurso. Campinas: Unicamp, 1992.

INSTITUTO BRASILEIRO DE GEOGRAFIA E ESTATISTICA. Acesso em: 31 maio 2020. Disponível em: https://cidades.ibge.gov.br/brasil/mg/espirito-santo-dodourado/panorama.

ORLANDI, E. P. Língua brasileira e outras histórias: discurso sobre a língua e o ensino no Brasil. Campinas: RG, 2009.

ORLANDI, E. P. Discurso em análise: sujeito, sentido e ideologia. Campinas, SP: Pontes Editores, 2012

ORLANDI, E. P. Análise de discurso: princípios e procedimentos. 6. ed. Campinas, SP: Pontes, 2010.

PÊCHEUX, M.. Semântica e discurso: uma crítica à afirmação do obvio. Trad. Eni Pulcinelli Orlandi [et al.]. 2. ed. Campinas, SP: UNICAMP, 1997.

PORTELli, A. História oral como gênero. Projeto História, Programa de Estudos PósGraduados em História da PUC/SP. São Paulo: EDUC, n. 22, 2001.

PORTELLI, A. Tentando aprender um pouquinho. Algumas reflexões sobre a ética na História Oral. Projeto História, Programa de Estudos Pós-Graduados em História da PUC/SP. São Paulo: EDUC, n. 15, 1997.

SOCORRO DE DEUS, M.; MARTINS DA SILVA, M. História das festas e religiosidades em Goiás. Goiás: Alternativa, 2003.

WILLIAMS, R. Marxismo e literatura. Rio de Janeiro: Zahar, 1979. 
Linguagens - Revista de Letras, Artes e Comunicação - ISSN 1981-9943

Blumenau, v. 13, n. 2, p. 334-350, maio/ago. 2019

DOI: http://dx.doi.org/10.7867/1981-9943.2019v13n2p334-350

ZUNTHOR, P. Introdução à poesia oral. São Paulo: Hucitec, 1997. 